\title{
Factors Affecting Employees' Attitudes and Tendency to Resign Caused by Organizational Change
}

\author{
HUỲNH TH! THU THANH \\ HCM University of Technology \\ Email:httthanh@hcmut.edu.vn, thanhhuynh306@gmail.com \\ CAO HÀO THI \\ HCM University of Technology \\ Email: chthi@hcmut.edu.vn
}

ARTICLE INFO

Article history:

Received:

June 11, 2013

Received in revised form

Aug. 12, 2013

Accepted:

Dec. 31, 2013
Keywords:

influential factors, organizational change, attitudes toward organizational changes, resignation tendency.

\section{ABSTRACT}

Organizational change is inevitable for survival and growth in the current dynamic business environment. Under the pressure of external and internal environments such as economic policies, behaviors of competitors, visions of companies, mergers, acquisitions, etc. every organization is forced to change. However, organizational change does not always bring expected results for all organizations. The most common reason for the failure of organizational change is the employees' resistance to change. This study aims at evaluating factors that affect acceptance, resistance and resignation among employees when organizational change takes place. The results showed that employees' commitment to and trust in organization have positive effects whereas perception of status loss has negative effects on acceptance of organizational change. On the other hand, commitment and trust of employees with organization have negative effects whereas workplace stress has positive impacts on the resistance to organizational change. Additionally, employees with resistance to changes tend to quit their jobs. Goodness of fit of the general model based on path analysis is $64.6 \%$. 


\section{INTRODUCTION}

Today's society is constantly moving and offers non-stop challenges of change. The development and global competition boost pressure on organizations, requiring from them certain changes to rapidly adapt to environments and quickly seize opportunities for development (Fay et al., 2004). Results from these efforts to change, however, are not usually as expected. According to Beer \& Nohria (2000), as cited by Valoka et al., 2005 , up to $70 \%$ of change initiatives failed, which indicates that implementation of changes to achieve established goals is not easy.

Among important issues while implementing organizational changes, it does not matter how corporate strategies, organizational structure or culture change but how to make employees accept those changes (Kotter et al., 2002). Managers, therefore, need to be aware of the impact of change on employees' thoughts, feelings and behavior, thereby coming up with specific measures to deal with certain situations in order to enhance the support of employees and increase the success in the process of change.

This study aims to discover the factors that influence employees' attitudes toward organizational changes and resignation intentions, proposes solutions to the improvement of the ability to accept changes and/or limit employees' resistance to changes, and provides management implications.

\section{THEORETICAL FRAMEWORK AND HYPOTHESES}

George \& Jones (2002) pointed out "An organization is a collection of people who work together to achieve individual and organizational goals." An organizational change is an active reformation aimed at creating greater corporate competitiveness ( $\mathrm{Yu}, 2009)$. It may be an application of new technologies, a strategic movement or shift, reorganization of production lines, corporate linking or merging with another business, restructuring of sales departments and an attempt to optimize corporate culture, or it is just simply a shift in working conditions or change of managers (Nguyễn Thị Bích Đào, 2009).

According to Appelbaum et al. (1998), an organization needs to change due to: (1) pressure of the external environment, including the behavior of competitors, government regulations, policies, economic conditions, or technological advances; and (2) internal demand for changes, including corporate missions and visions, purchase of new technology, mergers or acquisition, and so forth. 
There have been many studies of organizational change in different aspects. When studying the impact of change in the workplace, Levy (1986) takes interest in the impact on employees themselves, including their works as well as relationships with their colleagues. The study indicates that changes have a strong impact on individual employees, their perception of organization, their life and job satisfaction.

Armenakis et al. (1993) shows the plans accompanying change efforts are a major concern to employees. The authors note that once specific plans are set and efforts to change the organization are made, employees feel more satisfied. The situation that commonly makes employees feel shy or express opposition is that they do not know in advance or do not know the extent to which the change impacts on them (Vakola et al., 2005). Alannah (2006) suggests that the employee's attitude is influenced by three factors: frequency of change, impacts of change and plans to participate in the change.

In general, previous studies often focus on measures supporting successful change such as achieving specific plans to change, providing sufficient information (Nerina et al., 2004) and the leading role of the management (Nguyễn Thị Bích Đào, 2009). However, they failed to focus on an important aspect - attitudes of employees towards changes - and pinpoint the causes of positive or negative attitudes towards changes taking place in their organizations. This is essential as positive attitudes contribute most to successful change, otherwise all changes end in failure.

Vakola et al. (2005) studies the relationship between job stress, organizational commitment and employee's attitudes towards organizational change. The authors note that stress reduces organizational commitment and increases resistance to change and resignation intentions. In contrast, commitment creates positive impact on the attitude of acceptance, enhancing employee's satisfaction. Moreover, Yu (2009) refers to the awareness of employees and extensively researches on the role of stress and how stress management can affect employee's behaviors toward changes.

Acceptance of change is excitement and happiness to support the change (Vakola et al., 2005). When highly-appreciated employees engage in their jobs, they easily accept all the tasks associated with change initiatives. In this case, they are more likely to be aware that their organization is fully prepared for necessary changes to meet the goals of the organization.

On the contrary, resistance to change reflects some anger or fear related to uncertainty and ability to cope with changes (Vakola et al., 2005). Even if people are not satisfied 
with the current state of affairs, they still fear that any changes only make things worse. This fear may stem from the belief that changes have a negative impact or is simply a general fear, which creates a state of unwillingness to accept changes and quite negative reactions.

When employees face uncertainty, they often fear that the position, workload, and even the current status will be affected. They suspect that their skills may be outdated to handle new tasks. In addition, employees perceive change as a threat to their career path and finance, thereby possibly losing intangible features associated with the current working environment, such as power and prestige (Callan, 1993) and as a result, having a negative attitude and resistance to change. Accordingly, the following hypothesis $\mathrm{H} 1$ is developed:

Hypothesis H1a. Perception of uncertainty in organizational change negatively affects employee's acceptance of change.

Hypothesis H1b. Perception of uncertainty in organizational change positively affects employee's resistance to change.

Acquisition, suspicion, stress and some other personal reactions related to the change are all that need to be considered within the scope of change (Armenakis et al., 1993). A change clearly causes suspicion and stress, thus hindering success. The stress itself diminishes work efficiency and satisfaction in the organization. Caused by organizational change, it may create a negative attitude, thus becoming a factor which mounts the resistance to change (Vakola et al., 2005). Therefore, the proposed hypothesis $\mathrm{H} 2$ is as follows:

Hypothesis H2a. Job stress during organizational change negatively affects employee's acceptance of change.

Hypothesis H2b. Job stress during organizational change positively affects employee's resistance to change.

Trust in institutions shows a positive link between the members and the organization and promotes collaboration, sharing creativity and innovation. Based on a study by Deluga (1994), trust falls into three categories: employee's trust, trust in the leadership and trust in peers. When employees have confidence, they will increase interest in their career, adopt a positive viewpoint on matters, and more easily accept changes. They make better voluntary effort to accomplish the tasks. As such, hypothesis H3 is proposed: 
Hypothesis H3a. Trust in organization positively affects employee's acceptance of change.

Hypothesis H3b. Trust in organization negatively affects employee's resistance to change.

Organizational commitment plays an important role in employee's acceptance of change. When employees show their commitment to the organization, they are willing to accept organizational change if it is deemed beneficial (Lau et al., 1995). But other studies suggest that even if employees have a strong commitment to their organization, they may resist change once being aware that it is a threat to their interests (Vakola et al., 2005). These studies also show that there is an influence of organizational commitment and employee's attitude toward change. With high commitment to the organization, they would be willing to support and make effort to implement a change, thus resulting in a positive attitude toward change. For this reason, hypothesis $\mathrm{H} 4$ is suggested as follows:

Hypothesis H4a. Organizational commitment positively affects employee's acceptance of change.

Hypothesis H4b. Organizational commitment negatively affects employee's resistance to change.

Resignation intention refers to employee's intention to leave his current job and look for alternative employment opportunities (Lin et al., 2005). In organizational change, employees face uncertainty. They fear that the current position, workload, or even work location and all others will be affected. They suspect their skills may be outdated, causing obstacles to handle new tasks or their personal traits do not fit the new undertaken tasks. All inferences and ambiguities may create adverse effects on credible relationships between employees and the organization, manager and his peers, thereby reducing work satisfaction and bringing about resistance to change. Given a stronger opposition, employees tend to leave the organization. Having faith in the organization, on the other hand, employees are aware that a change is necessary and accept it without the resignation intention (Vakola et al., 2005). Concerning this, hypotheses H5 and H6 are recommended:

Hypothesis H5. Acceptance of change negatively affects employee's resignation intention on the occurrence of change. 
Hypothesis H6. Resistance to change positively affects employee's resignation intention on the occurrence of change.

\section{RESEARCH MODEL}

The research model is built from model for estimating employee attitudes in organizational change by Vakola et al. (2005). One limitation of Vakola et al. (2005) is that there lacks an assessment of the impact of preconception of change on employee's attitudes and trust. This study has yet to analyze how acceptance of change or resistance to change affects resignation intention; however, the limitation of Vakola et al. (2005), in combination with $\mathrm{Yu}$ (2009), allows the influential factors on employee's attitudes, including perception of change, organizational commitment and employee's trust, to be identified and the research model to be developed as in Figure 1.

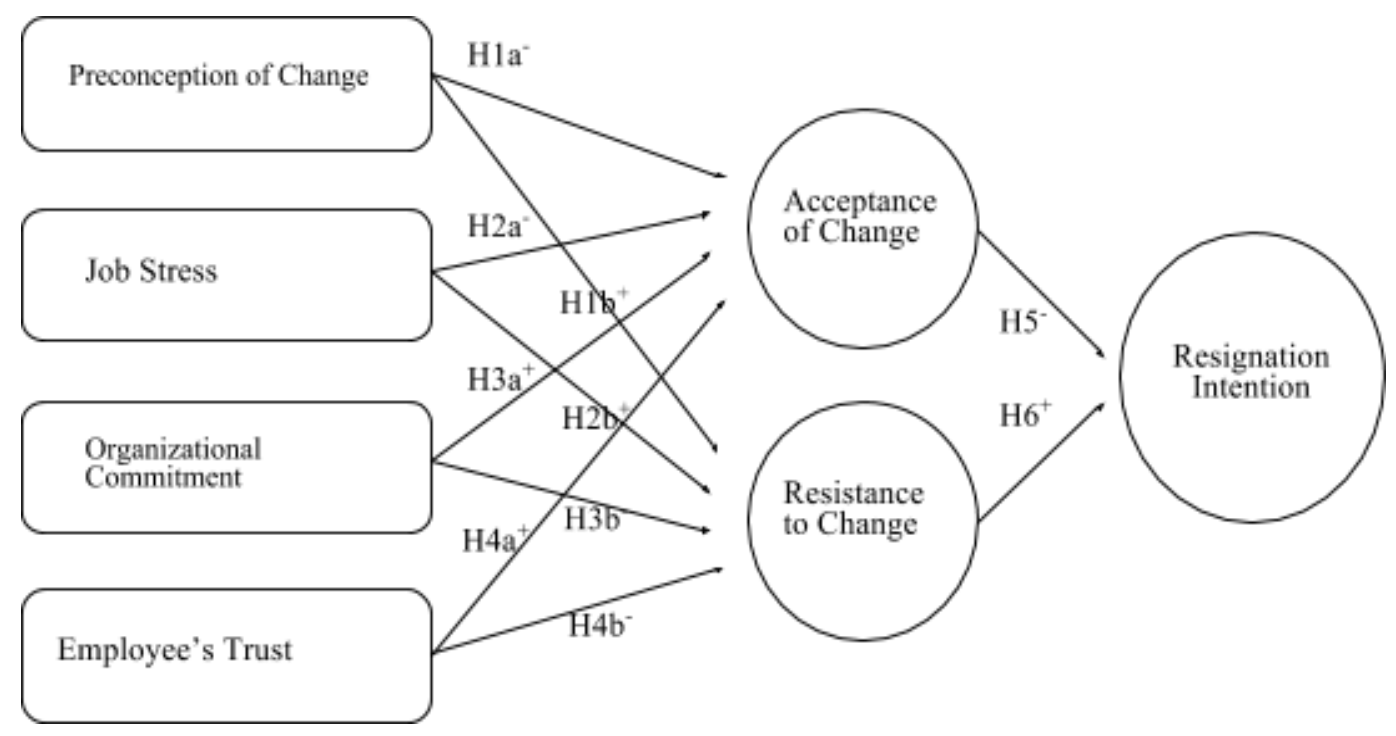

Figure 1: Model of Employee's Attitudes in Organizational Change

\section{METHODOLOGY}

The research is conducted with two main steps: preliminary research and main research. Preliminary qualitative research is carried out through discussions with experts to evaluate, modify and adjust scales to organizations in Vietnam. Seven members participating in discussion are professionals working in HCMC-based organizations that have carried out changes. Preliminary quantitative research is carried out to undertake preliminary assessment of the reliability of the designed scales and make necessary 
adjustment. Survey samples are collected by means of online interviews (google docs) for a total of 61 valid feedback items.

Main research employs the questionnaire modified in the preliminary one. The questionnaire has been sent to the employees working in organizations that have carried out a certain number of such changes as in structures, cultures, processes, policies, managers, work positions, etc. within HCM City from 2011 until now. Respondents are interviewed via printed and online research tools, coming up with a total of 206 feedback forms. After the data have already been examined, the total number of valid items is 200 .

The concepts of the study are measured by available scales and have been tested by Vakola et al. (2005) and Yu (2009). There are seven concepts with a total of 34 observed variables used as shown in Table 1. Five-level Likert scale from 1 (completely disagree) to 5 (completely agree) is employed to measure the variables.

Table 1: Origin of the Scales

\begin{tabular}{lcl}
\hline \multicolumn{1}{c}{ Source } & Number of Variables & \multicolumn{1}{c}{ Concept } \\
\hline Vakola et al. (2005) & 6 & Job stress \\
Yu (2009) & 9 & Employee's Perception of Change \\
Yu (2009) & 4 & Employee's Trust \\
Vakola et al. (2005) & 6 & Organizational Commitment \\
Vakola et al. (2005) & 4 & Acceptance of Change \\
Vakola et al. (2005) & 3 & Resistance to Change \\
Lin et al. (2005) & 2 & Resignation Intention \\
\hline
\end{tabular}

After preliminary quantitative analysis, three observed variables in the scales - job stress, employee's perceptions, and organizational commitment - are eliminated, because a poor item-total correlation $(<0.3)$ makes the scales have a low reliability. The remaining 31 variables ( 22 independent variables and 9 dependent ones) are included in 
the main study. The elimination of these three variables does not affect the content values of the scales.

\section{RESULTS}

\section{a. Descriptive Statistics:}

Of the 200 items collected, male respondents take out $63.5 \%$ and female respondents, $36.5 \%$. The $25-30$ age bracket of the sample accounts for $72.5 \%$ followed by the $30-35$ bracket, $16.5 \%$. The remaining age groups represent small percentages of the sample. In terms of marital status, unmarried respondents take out a large proportion of up to $75.0 \%$, whereas married ones, $25.0 \%$. Work experience of 1 to 5 years accounts for $65.0 \%$, followed by 6 to 10 years, $18.5 \%$, less than 1 year, $13.5 \%$, and over 11 years, $3.0 \%$.

Statistics of changes show that change of managers and structural change are the two cases most often occurring in organizations, representing over $20 \%$ each. Changes in positions, processes and policies account for nearly $15 \%$ each. Meanwhile, mergers and cultural changes take out a low proportion, equivalent to $5 \%$.

Regarding operation fields of surveyed companies, $24 \%$ are in trading and service sector, followed by manufacturing, construction, electronics and telecommunication, over $15 \%$ each, and the others such as finance and accounting, healthcare, education, securities, etc., less than $10 \%$.

\section{b. EFA and Reliability Analysis:}

A total of 22 independent variables after the preliminary research are included in factor analysis. KMO index equal to 0.777 and sig. $=0.000$ illustrates that factor analysis is appropriate for the present data. The factor analysis is based on Eigen value parameter; only those factors going with Eigen value greater than 1 are retained in the model now that after standardized, each original variable has a variance equal to 1 . Varimax method is employed to minimize the number of variables with high factor loadings in the same factor. Factor analysis results are presented in Table 2.

From the theoretical model with four factors affecting employee attitudes, the study develops five factors, including organizational commitment (Commit), job stress (Stress), employee's trust (Trust), perception of status loss (Percep1) and perception of work overload (Percep2). In particular, the scale of preconception of change (Precept) is split into two separate factors different from that of the original model. According to $\mathrm{Yu}$ (2009), the scale of perception of change is multi-directional, that is, it connects with 
perception of status loss, insecurity or work overload. Therefore, two new factors are renamed as follows:

One with Eigen value $=2.961$ and five observed variables is labeled perception of status loss.

The other with Eigen value $=1.241$ and three observed variables is labeled perception of work overload.

The above extracted factors explain $59.80 \%$ of the observed variables. The values of factor loadings range from 0.575 to 0.833 and are generally acceptable.

Factor analysis is conducted for three dependent variables, including Acceptance of Change (Accept), Resistance to Change (Resist), and Resignation Intention (Resign). Results show that the studied concepts are unidirectional with Eigen value greater than 1 and the total variance extracted greater than 50\%. All factor score coefficients are greater than 0.5 .

Table 2: Results of Factor Analysis with Influential Factors

\begin{tabular}{llllllll}
\hline & & & & Factor & Observed Variable & Code \\
\hline 5 & 4 & 3 & 2 & 1 & & \\
\hline
\end{tabular}

0.741 I feel that the problems of the organization are also Commit21 my personal ones. I fell happy to stick with the organization in a long Commit20
term. 0.693 I would love to be a member of this homely Commit22
organization.

0.669 I continue my work here for it brings more benefits Commit24 than others.

0.575 I suppose that employees should be loyal to their Commit25 organization. 
0.833

0.791

0.711

0.661
During a change, I am afraid that my work will no Percep08 longer be appreciated.

It is predicted that in organizational change I may be Percep07 demoted.

It is predicted that in organizational change my Percep15 benefit will be reduced.

It is predicted that in organizational change my Percep10 future prospects would be unsure.
0.794

0.767

0.727

0.661
Changes prevent me from putting my workload Stress02 under control.

Changes make my work interfere with my personal Stress03 life and family.

Changes make me frequently work in longer hours Stress01 than stipulated.

In organization change my working conditions are Stress04 not good enough.
0.767

0.734

0.701

0.587
I believe that my colleagues are willing to help one Trust19 another.

I believe that my colleagues have adequate Trust 18 capabilities to respond to organizational change.

I believe that organizational change offers equal Trust16 treatment to all employees.

I believe that the organization will care what affects Trust 17 me when changes take place. 
0.812

It is predicted that in organizational change I will not Percep11 be able to adapt to new environment.

0.745

It is predicted that in organizational change my skills Percep13 will not sufficiently meet work requirements.

0.642 It is predicted that in organizational change my life Percep12 would change.

\section{$\begin{array}{llllll}1.241 & 1.366 & 1.687 & 2.961 & 4.705 & \text { Eigen value }\end{array}$}

59.80150.16638.47526.202 13.394 Explained Variation (\%)

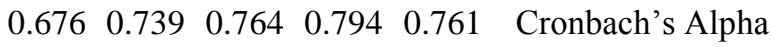

Cronbach's Alpha analysis shows that the reliability of the scales is satisfactory. Its values range between 0.676 (perception of work overload) and 0.911 (resignation intention).

\section{c. Multiple Linear Regression Analysis:}

The method used to analyze the research model and hypotheses is PATH (Pedhazur, 1982). The research model is deemed the equivalent of three regression equations. Results of the analysis are presented in Table 3.

Table 3: Results of Multiple Linear Regression Analysis

\begin{tabular}{|c|c|c|c|c|c|c|c|c|}
\hline & & & & & & & $\begin{array}{c}\text { Regression } \\
\text { Coefficient }\end{array}$ \\
\hline & Multicollinearity & $\begin{array}{c}\text { Level of } \\
\text { Significance }\end{array}$ & T-Statistic & $\begin{array}{c}\text { Standardized } \\
\text { Coefficient }\end{array}$ & $\begin{array}{c}\text { Unstandardized } \\
\text { Coefficient }\end{array}$ & Equation \\
\hline $\begin{array}{c}\text { Inflation } \\
\text { Factor }\end{array}$ & $\begin{array}{c}\text { Tolerance } \\
\text { of Variable }\end{array}$ & & & $\begin{array}{c}\text { Standardized } \\
\beta\end{array}$ & $\begin{array}{c}\text { Standard } \\
\text { Deviation }\end{array}$ & B Coefficient & \\
\hline & 0.000 & 4.720 & & 0.343 & 1.619 & (Constant) & (Accept) \\
\hline
\end{tabular}




\begin{tabular}{|c|c|c|c|c|c|c|c|c|}
\hline 1.384 & 0.723 & 0.000 & 4.812 & 0.333 & 0.080 & 0.384 & Trust & \\
\hline 1.323 & 0.756 & 0.000 & 3.718 & 0.251 & 0.075 & 0.281 & Commit & \\
\hline \multirow[t]{2}{*}{1.097} & 0.912 & 0.015 & -2.453 & -0.151 & 0.063 & -0.153 & Percep1 & \\
\hline & & 0.000 & 5.937 & & 0.390 & 2.314 & (Constant) & $\begin{array}{c}2 \\
\text { (Resist) }\end{array}$ \\
\hline 1.126 & 0.888 & 0.000 & 4.550 & 0.289 & 0.066 & 0.302 & Stress & \\
\hline 1.105 & 0.905 & 0.000 & -4.041 & -0.254 & 0.080 & -0.322 & Trust & \\
\hline \multirow[t]{2}{*}{1.182} & 0.846 & 0.001 & 3.372 & 0.219 & 0.073 & 0.245 & Percep1 & \\
\hline & & 0.000 & 4.419 & & 0.237 & 1.049 & (Constant) & $\begin{array}{c}3 \\
\text { (Resign) }\end{array}$ \\
\hline 1.000 & 1.000 & 0.000 & 8.791 & 0.530 & 0.084 & 0.737 & Resist & \\
\hline
\end{tabular}

Regarding the first equation with evaluation of the factors affecting employee's acceptance of change (Accept), the multiple regression analysis suggests the optimum model including such three factors as organizational commitment (Commit), employee's trust (Trust) and perception of status loss (Percep1). The three-factor regression model explains $31.3 \%$ of the total of factors with the impact on employee's acceptance of change.

The second equation evaluates the factors affecting resistance to change (Resist). The multiple regression analysis introduces another optimum model consisting of such three factors as job stress (Stress), perception of status loss (Percep1), and employee's trust (Trust). The model explained $28.7 \%$ of the total of factors affecting employee's resistance to change.

The third equation evaluates the resistance to change (Resist), considerably affecting resignation intention (Resign) with $\mathrm{R}^{2}=27.7 \%$. Yet, acceptance to change itself is not statistically significant to resignation intention.

Accordingly, by the test of the 12 research hypotheses, seven hypotheses (H1A, H1B, $\mathrm{H} 2, \mathrm{H} 3 \mathrm{~B}, \mathrm{H} 4 \mathrm{a}, \mathrm{H} 4 \mathrm{~b}, \mathrm{H} 5 \mathrm{a}$, and H7) are supported and five hypotheses (H2A, H2B, H3a, $\mathrm{H} 5 \mathrm{~b}$ and H6) are rejected. The model is shown in Figure 2.

The overall fit of the research model $-\mathrm{R} 2$ - according to the PATH model is:

$$
\mathrm{R}^{2}=1-\left(1-\mathrm{R}^{2}{ }_{1} *\left(1-\mathrm{R}^{2}{ }^{2} *\left(1-\mathrm{R}^{2}{ }_{3}\right) \quad\right. \text { (Pedhazur, 1982) }\right.
$$


where $\mathrm{R}^{2}{ }_{1}, \mathrm{R}^{2}{ }_{2}$, and $\mathrm{R}^{2}{ }_{3}$ are coefficients of determination of component regression model and the overall fit of the model $\mathrm{R}^{2}=64.6 \%$.

Tests of differences between groups of samples by T-test and ANOVA analysis demonstrate no significant differences as for employee's attitudes and resignation intention.

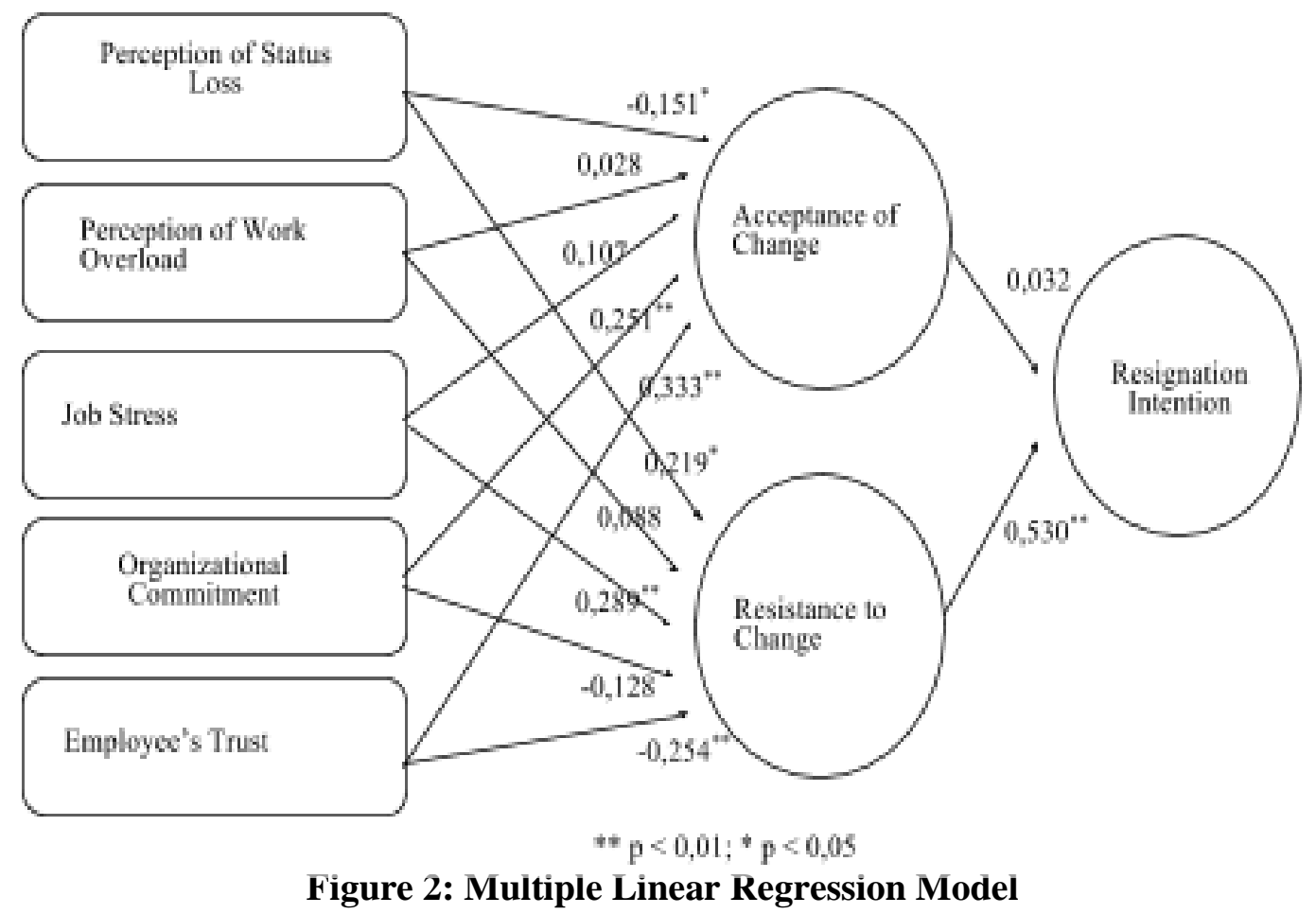

\section{DISCUSSION}

This research contributes a new model of employee's attitudes and behavioral tendencies in organizational change. The novelty of the study is also conveyed through the reconstruction of the scales appropriate to Vietnam's conditions. The application of the research model to examine and analyze new datasets will provide useful information for local as well as foreign businesses in need of reforms. The results support administrators with the management of changes, allowing organizational changes to yield positive results.

The results show: 
First, employees accept the change when they have trust $(\beta=0.333)$. With some trust, they realize that a change is necessary and believe that the organization will pay attention to their needs and resources necessary for the change and that their colleagues and superiors can afford certain supports for the change.

Second, organizational commitment is also an important factor affecting employee's acceptance of change $(\beta=0.251)$. When commitment is affirmed, employees should consider the organizations their families and feel content to be a member since their individual needs are satisfied by the organization. The findings, in addition, reinforce the previous findings of significance of commitment between the employee and the organization with successful change (Vakola, 2005; Yu, 2009).

Third, perception of status loss has a negative impact on employee's acceptance of change ( $\beta=-0.151)$. Employees, in organizational change, are often aware that this change will affect their current positions and fear that change would lessen their roles in the organization and reduce their influence on other employees; therefore they tend to resist the change to protect their own positions $(\beta=0.219)$.

Fourth, job stress has a strong impact on employee's resistance to change $(\beta=0.289)$. Changes not only may cause many serious disturbances in their lives and habits. Changes may also burden them with more work making them fail to control the workload and complete the tasks because of shortage of time, which leads to employees' resistance to change.

Fifth, resistance to change will lead to resignation intention $(\beta=0.530)$. Once the changes are not acceptable and they cannot integrate into new organizational cultures, employees will tend to leave their current jobs and look for new ones with more suitability.

Finally, acceptance of change has no statistical significance to resignation intention. It can be seen that employees can accept the change, but they are not completely satisfied with the work; therefore, resignation intention depends on many factors, not just considered through the impact of change.

\section{CONCLUSION}

\section{a. Management Implications and Recommendations:}

Given the current prolonged economic crisis, many businesses face challenges of undertaken changes to adapt to and overcome difficulties. General consensus among 
employees will yield necessary solidarity within the organization and success will be achieved. Based on the research results, a number of recommendations to improve acceptance of change as well as to handle resistance to change are outlined below:

Employee's trust can be created and expressed by their believing that "their colleagues are willing to help one another, their colleagues have adequate capabilities to respond to organizational change and the organization will care what affects employees." A collaborative work environment, thus, should be created to offer cooperation, group support, and effective interpersonal communication to enhance unity. As for the upcoming changes, employees should be informed of what new tasks are and whether these tasks exceed their expertise. If it is the case, the organization needs a support group or advisory experts to guide the staff through clear, specific task-solving strategies. By listening to employee's thoughts and noting encountered difficulties, managers show that they always accompany employees rather than demanding too much from or abandoning employees.

Employee's commitment is reflected through the feeling of "happiness for being stick with the organization, benefits from the organization, loyalty, and the view of organization's problems as personal ones." To increase commitment, organizations should first have transparent development policies and strategies. Appropriate goals and orientation will facilitate the employee's trust, his commitment and desire to become an important factor in the organization, striving to achieve common goals. Next, tasks are appropriately assigned besides skill development programs for improving employee's job satisfaction and thereby enhancing commitment.

To limit employee's resistance to change, it is a need to understand who or which section the change affects. The affected should then be informed that change is necessary and that criteria for rewards of contributions and promotion opportunities are created for them. Increasing tensions also strengthen resistance, being likely to occur when the workload goes beyond control or in case of overtime or unsafe working conditions. To avoid such, the organization, therefore, needs to plan the change carefully with proper schedule, and reduce tension and ambiguity.

Resistance to change manifests itself through deliberate duty evasion, postponement in new tasks, hindrance to the implementation, demand for more time and money for implementation, etc. If employees show one of these indicators and measures to limit resistance to change no longer work, then a plan for staff change should be prepared to 
offset positions. This is because once an employee is no longer interested in the job, productivity and quality will decrease, and then a replacement is needed.

In brief, to facilitate acceptance of change, organizations must have an efficient organizational culture. They should not wait until a change occurs to take certain interest in employee's commitment and trust. Instead, organizations, right from the beginning, should build a long-term committed working environment, allowing themselves to adapt quickly to the changes. Once the staffs have confidence and commitment to the organization, they will be loyal and have trust, and any organizational changes undertaken are seen as necessary and they have more positive attitudes to support.

\section{b. Limitations and Suggestions for Further Studies:}

Research on employee's attitudes in organizational change produces useful information for managers and organizations who long to conduct changes. However, the results obtained reflect certain limitations. Target sample of the research is limited to HCMC-based companies with a moderate sample size; therefore, the results will be better if the sample is larger.

In addition to the factors affecting employee's attitudes mentioned in the model, there are many others that have not been considered, such as frequency of change (Glick et al., 1995), and personal traits (Janou, 2006). Resignation intention is affected by many factors besides the aforementioned resistance to change (with $\mathrm{R}^{2}$ equaling $27.7 \%$ only). Some of them have been explored by previous studies, such as job satisfaction (Lin et al., 2005), work environment, company policies, and so forth. This is also a limitation, being open for further research

\section{References}

Appelbaum, S.H., N. St-Pierre \& W. Glavas (1998), "Strategic Organizational Change: The Role of Leadership, Learning, Motivation and Productivity”, Management Decision, Vol. 36(5), pp. 289301.

Armenakis, A.A., S.G. Harris \& K.W. Mossholder (1993), “Creating Readiness for Organizational Change", Human Relations, Vol. 46(6), pp. 681-703.

Beer, M. \& N. Nohria (2000), "Cracking the Code of Change”, Harvard Business Review, Vol. 78(2), pp. 133-141.

Callan, V.J. (1993), "Individual and Organizational Strategies for Coping with Organizational Change", Work \& Stress, Vol. 7(1), pp. 63-75. 
Deluga, R.J. (1994), "Supervisor Trust Building, Leader-Member Exchange and Organizational Citizenship Behavior", Journal of Occupational and Organizational Psychology, Vol. 67(4), pp.315-326.

Fay, D. \& H. Lührmann (2004), "Current Themes in Organizational Change”, European Journal of Work and Organizational Psychology, Vol. 13(2), pp.113-119.

George, J.M. \& G.R. Jones (2002), Understanding and Managing Organizational Behavior ( $3^{\text {rd }}$ ed.), Pearson Prentice Hall, New Jersey.

Huber, G.P. \& A.H. Van de Ven (1995), Longitudinal Field Research Methods: Studying Processes of Organizational Change (Organization Science), SAGE Publications, pp. 126-154.

Jimmieson, N.L., D.J. Terry \& V.J. Callan (2004), “A Longitudinal Study of Employee Adaptation to Organizational Change: The Role of Change-Related Information and Change-Related SelfEfficacy”, Journal of Occupational Health Psychology, Vol. 9(1), pp. 11-27

Kotter, J.P. \& D.S. Cohen (2002), The Heart of Change: Real-life Stories of How People Change Their Organizations, Harvard Business Review Press.

Lau, C.M. \& R.W. Woodman (1995), "Understanding Organizational Change: A Schematic Perspective”, The Academy of Management Journal, Vol. 38(2), pp. 537-554.

Levy, A. (1986), "Second-order Planned Change: Definition and Conceptualization", Organizational Dynamics, Vol.15, pp.5-20.

Lin, Nan-Hong \& Chiang Yu-Han (2005), “A Study of Relationship between Organizational Change Perceptions and Turnover Intention in the Financial Industry - The Mediating Effects of Job Satisfaction and Job Stress".

Nguyễn Thị Bích Đào (2009), "Quản lý những thay đổi trong tổ chức”, Tạp chí Khoa họ ĐHQGHN, Vol. 25(3), pp.159-166.

Pedhazur, E.J. (1982), Multiple Regression in Behavioral Research (2nd ed.), Harcourt College Publishers.

Rafferty, A.E. \& M.A., Griffin (2006). "Perceptions of Organizational Change: A Stress and Coping Perspective", Journal of Applied Psychology, Vol. 91(5), pp.1154-1162.

Vakola, M. \& I. Nikolaou (2005), “Attitudes Towards Organizational Change: What is the Role of Employees' Stress and Commitment?” Employee Relations, Vol. 27, pp. 160-174.

Vos, J. (2006), The Role of Personality and Emotions in Employee Resistance to Change (Master's Thesis), Erasmus University Rotterdam.

Yu, Ming-Chu (2009), "Employees' Perception of Organizational Change: The Mediating Effects of Stress Management Strategies”, Public Personnel Management, Vol. 38(1), pp. 17-32. 